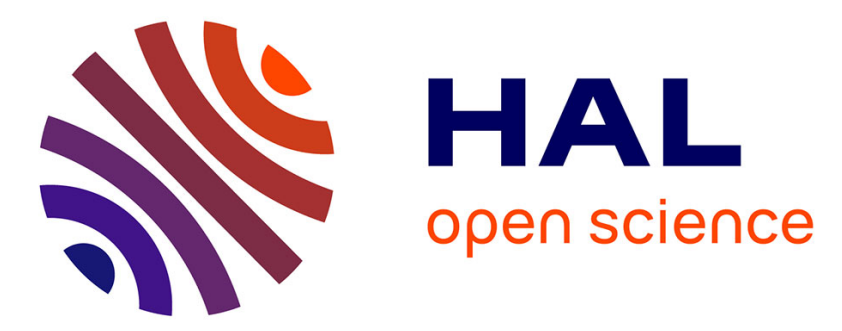

\title{
OPTICAL INVESTIGATION OF HIGH-FIELD CONDUCTION AND PREBREAKDOWN IN A DIELECTRIC LIQUID
}

C. Brosseau, Abderrahmane Beroual

\section{- To cite this version:}

C. Brosseau, Abderrahmane Beroual. OPTICAL INVESTIGATION OF HIGH-FIELD CONDUCTION AND PREBREAKDOWN IN A DIELECTRIC LIQUID. IEEE Transactions on Dielectrics and Electrical Insulation, 1994, 1 (3), pp.397-402. hal-00141652

\section{HAL Id: hal-00141652 \\ https://hal.science/hal-00141652}

Submitted on 25 Apr 2007

HAL is a multi-disciplinary open access archive for the deposit and dissemination of scientific research documents, whether they are published or not. The documents may come from teaching and research institutions in France or abroad, or from public or private research centers.
L'archive ouverte pluridisciplinaire HAL, est destinée au dépôt et à la diffusion de documents scientifiques de niveau recherche, publiés ou non, émanant des établissements d'enseignement et de recherche français ou étrangers, des laboratoires publics ou privés. 


\title{
Optical Investigation of High-field Conduction and Prebreakdown in a Dielectric Liquid
}

\author{
C. Brosseau \\ CERMO, Saint-Martin-d'Hères, France. \\ and $\mathrm{A}$. Beroual \\ Département d'Electrotechnique, CEGELY, \\ Ecole Centrale de Lyon, France
}

\begin{abstract}
Light emission studies of the high-field conduction and prebreakdown phenomena in a mixture of mono and dibenzyltoluene (M/DBT), used as polypropylene impregnant in the all-film capacitor technology, have been undertaken to gain insight into the underlying physical mechanisms responsible for these processes. The absorption spectrum of this fluid, in the UV region, shows the appearance of structured bands at 348,366 and $386 \mathrm{~nm}$ indicating a luminescence process via anthracene and 9-methylanthracene impurities at a concentration of $3 \times 10^{-3} \mathrm{~mol} / \mathrm{l}$. Optical and electrical measurements were performed simultaneously on the electrically stressed fluid. Electroluminescence of the impurities contained in M/DBT has been investigated using a new uniform field electrode arrangement. The light inception stress was determined to be $\sim 20 \mathrm{~V} \boldsymbol{\mu m}^{-1}$ for ac excitation $(50 \mathrm{~Hz})$. Configurations with different interfacial situations were studied and we have evidenced a correlation between charge injection and electroluminescence activity. Spectral analysis of the light radiated by streamers in $M / D B T$ in a needle-plane electrode geometry, under step voltage $(1$ to $50 \mu \mathrm{s}, 30 \mathrm{kV}$ ) revealed, for both polarities, the presence of $\mathrm{H}_{2}$ and $\mathrm{C}_{2}$ characteristic bands emerging from a continuum corresponding to the dissociation and recombination of molecular fragments.
\end{abstract}




\section{INTRODUCTION}

$\mathrm{T}$ HERE is much concern with the development of new insulating materials particularly when these materials are based on solid-liquid combinations, e.g. oil-impregnated polymer film capacitors for space applications. This has intensified interest in synthetic dielectric fluids that are compatible with polymers such as polypropylene. As the physical mechanisms of high-field electrical conduction and breakdown are the key phenomena to be understood, a large body of work has been focused on simple liquids and technological fluids resulting in a fundamental understanding of many properties [1-12]. Much less attention has been given to explain interfacial aspects which are predominant for solid-liquid combinations. In previous papers we reported experimental work on the ac conduction phenomena of a thin capacitor impregnant layer (typically $15 \mu \mathrm{m}$ ) at high electric fields for several interfacial situations (metal and insulating boundaries) [3]. The features revealed by these experiments, designed to simulate actual conditions occurring in all-film power capacitors, show a strong field dependence on the liquid electric losses (at a frequency of $50 \mathrm{~Hz}$ ) and according to that, the liquid layer is in contact with a metallic or a polymer interface. It was argued that charge carrier injection in the neighborhood of the interface is the dominant contribution of the high-field conductivity [4]. Mechanisms of electric breakdown of these thin liquid layers were also discussed in an earlier article [9].

Historically, insulating fluids have been characterized by employing traditional electrical measurements (e.g. bulk breakdown, losses, resistivity). In the recent past, it has become very clear that significant improvements in the characterization of dielectric fluids under stress can be achieved through exploitation of optical techniques [10-18]. As part of our continuing effort to understand liquid conduction mechanisms at high electric fields and prebreakdown phenomena, we have two goals in this paper: firstly, to show that electroluminescence may provide information on the charge carrier injection mechanism and secondly to explore the prebreakdown events by the spectral analysis of the light radiated by streamers in $\mathrm{M} / \mathrm{DBT}$ under step voltage (1 to $50 \mu \mathrm{s}$ ) in a point-plane configuration.

Section 2 gives the experimental conditions under which the following observations were made. Section 3 presents the experimental results concerning the electroluminescence activity and the spectral analysis of prebreakdown phenomena. Finally some concluding remarks are drawn in Section 4.

\section{EXPERIMENTAL}

The liquid used in this investigation was $\mathrm{M} / \mathrm{DBT}$ ( $\mathrm{a}$ mixture of mono $\mathrm{C}_{14} \mathrm{H}_{14}$ and dibenzyltoluene $\mathrm{C}_{21} \mathrm{H}_{20}$ ) of

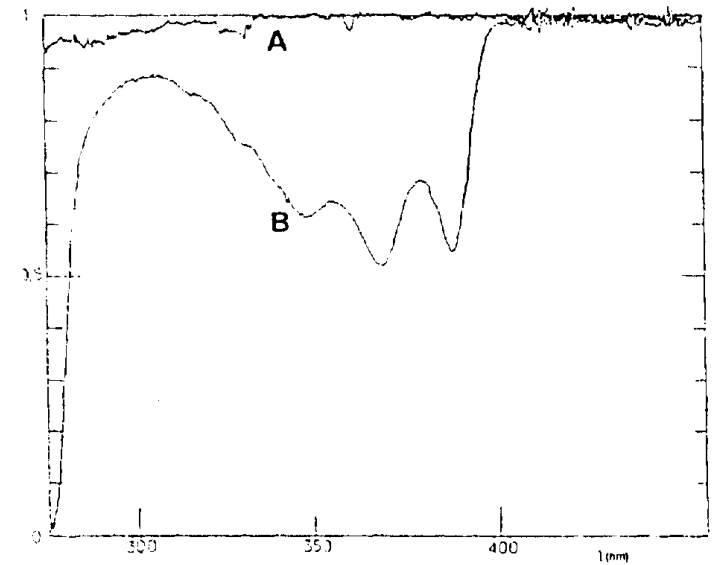

Figure 1.

UV absorption spectra of (a) spectroscopic-grade cyclohexane and (b) M/DBT in spectroscopicgrade cyclohexane.

relative permittivity $\varepsilon(298 \mathrm{~K})=2.66$. This aromatic insulating liquid of low viscosity $(\nu(293 \mathrm{~K})=6.3 \mathrm{cS})$ is a capacitor impregnant whose spectroscopic and dielectric properties have been carefully characterized $[3-4,10]$. Quality of the fluid was controlled throughout the experimental work (conductivity $\leqslant 10^{-13} \Omega^{-1} \mathrm{~m}^{-1}$ and water content $<5 \mathrm{ppm}$, both measured at room temperature). The UV absorption spectrum of $M / D B T$ (Figure 1) reveals three structured bands at 348,366 and $386 \mathrm{~nm}$. Since this saturated hydrocarbon is expected not to absorb in the ordinary UV or visible regions, due to the high energy required for a transition $\sigma \rightarrow \sigma^{*}$, we have found that these absorption bands can be attributed to unsaturated impurities contained in M/DBT (anthracene, 9methylanthracene) at a concentration equal to $3 \times 10^{-3}$ mol $\mathrm{I}^{-1}[10]$. However, UV spectra indicate that these luminescent impurities degrade substantially when irradiated with a mercury lamp. After only $3 \mathrm{~h}$, the intensity in most bands decreased significantly [10].

Polymer film was biaxially-oriented and both sides roughened polypropylene $(\varepsilon(298 \mathrm{~K})=2.20$, hereafter PP) of thickness $15 \mu \mathrm{m}$. Two kinds of electrodes were used for the experimental work reported here. For the purpose of electroluminescence measurements, we have constructed a special uniform field electrode arrangement which enables us to work with a controlled thickness of liquid. The arrangement contains a cell chamber made of a Teflon $^{\text {TM }}$ cylinder with plane electrodes (one in stainless steel which has been carefully polished with a very fine emery paper, the other prepared by vacuum depositing indium oxide on a glass substrate which is transparent in the UV-visible domain). Light is detected with a photomultiplier (RCA 7265 having a flat response in spectral 


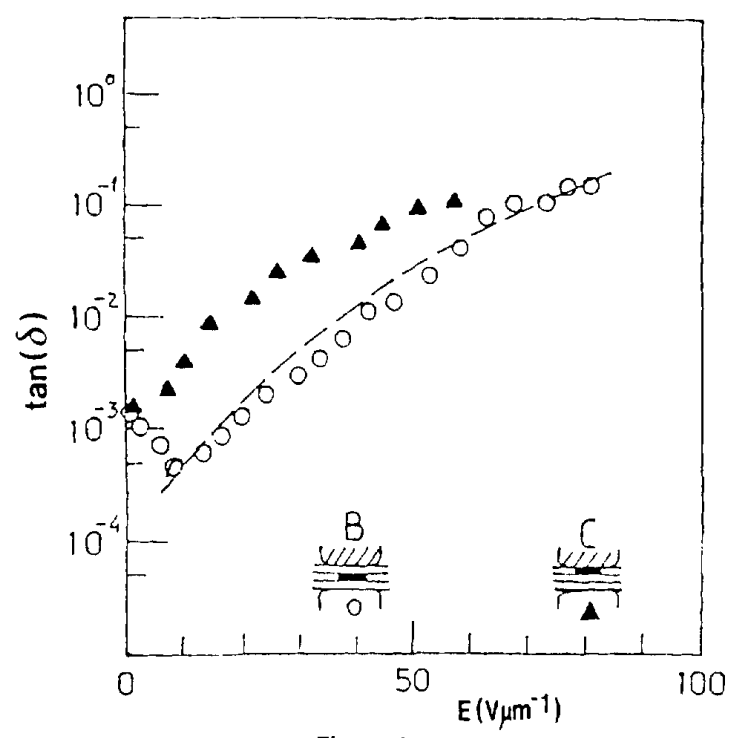

Figure 2.

Comparison of the liquid electric losses $\tan \delta(50$ $\mathrm{Hz}$ ) for the different interfacial configurations vs. electric field $E\left(\mathrm{~V}_{r m}, \mu \mathrm{m}^{-1}\right)$. Room temperature. Cartoons of the two different configurations of the test cell. B configuration: $15 \mu \mathrm{m}$ liquid thickness sandwiched between dry PP disks. C configuration: $15 \mu \mathrm{m}$ liquid thickness between the electrode and dry PP disks. The liquid cavity is represented in black while the transparent electrode is hatched. The dashed line is a fit according Equation (1).

range of wavelengths 200 to $900 \mathrm{~nm}$ ) facing the transparent electrode. To minimize the dark noise, the tube was cooled to $-20^{\circ} \mathrm{C}$. The test cell was vacuum filled with $\mathrm{M} / \mathrm{DBT}$ then evacuated of gas for a day before each test. It was then mounted in an electrically screened chamber. This chamber, together with all the optical components were assembled in a light-tight box. To investigate the role of the interface, two configurations (named $\mathrm{B}$ and C) with PP/liquid/PP (or metal) interfaces were used by covering electrodes with PP disks of the same dimension as the spacer but without internal holes. A diagram of configurations $B$ and $C$ is given in Figure 2. These configurations contain PP disks and a PP spacer with three calibrated holes, filled by $M / D B T$, playing the role of liquid reservoirs. The liquid gap is controlled by the polymer thickness $[3,4,9,10]$. tan $\delta$ measurements were made using a Tettex 2801 Schering bridge. All experiments have been carried out at room temperature. Extraction of the liquid losses from the total losses of the test cell requires careful consideration and follows the same procedure described in [3].
Test conditions for the study of prebreakdown events have been described in detail elsewhere [17], however for completeness we recall here briefly the main features. The experimental setup consists of a square wave generator ( $50 \mathrm{kV}$ maximum), a test cell containing the fluid sample and the optical and electrical measuring systems. The test cell, made of a Teflon cylinder contains two observation windows made of quartz. The electrode system is of the point-plane type: the radius of curvature of the needle was $3 \mu \mathrm{m}$ and the electrode gap was $2 \mathrm{~mm}$. The $10 \mathrm{~mm}$ diameter plane electrode was covered by a PP film to prevent breakdown degrading the electrode surface. Light emitted by prebreakdown phenomena was detected either by a photomultiplier (the same as above or thanks to an optical multichannel analyzer (OMA 3?? EG\& G Princeton Applied Corporation 1460) coupled to a spectrograph equipped with a series of gratings $(20$, $3.3,1.2 \mathrm{~nm} / \mathrm{mm}$ ).

\section{RESULTS AND DISCUSSION}

The results will be presented in two Subsections. In the first, the relationship between electroluminescence and conduction is presented while in the second one, attention is focused on the spectral analysis of the light emitted by the propagation of low-density structures (streamers).

\subsection{ELECTROLUMINESCENCE AND CHARGE INJECTION}

Reproducible liquid losses have been plotted for the different interfacial configurations employed in Figure 2. Although a detailed discussion of this graph was done in a previous paper [3], a short comment may be useful at this point. This graph (plotted in a semilogarithmic scale) shows a strong dependence of $\tan \delta$ vs. electric field. Since electronic emission from cathode is negligible for fields smaller than $100 \mathrm{~V} \mu \mathrm{m}^{-1}$, ionic conductivity will predominate. We have already proved that the field enhanced ionic dissociation in the bulk of the liquid plays a limited part in the high-field regime. The evaluation of the nonlinear field dependence losses for ionic conduction was done in a recent series of articles [3-4]. The governing equation for the losses caused by unipolar injection of ions into a nonpolar fluid, starting at a double layer structure near the interface, may be written as

$$
\tan \delta(E) \sim \int_{0}^{\pi} E^{-1 / 2} q_{0}(E) G\left[(E \sin u)^{1 / 2}\right](\sin u)^{3 / 2} d u
$$

The expression for $G$ is $G(x)=\left[K_{1}(x)\right]^{-1}$ with $K_{1}$ being the modified Hankel function and $q_{0}(E)$ is the bulk ionic density [3]. 
The light inception voltage was measured to determine the onset electric field necessary for electroluminescence emission under ac stress excitation and was found to be $\sim 1 \mathrm{kV}_{r m s}$ (i.e. $\simeq 20 \mathrm{~V} \mu \mathrm{m}^{-1}$ ) for the two configurations studied. This value corresponds to the rapid field increase of the losses. Here we mention that the light emitting centers are the luminescent impurities in M/DBT, which contain conjugated double bonds. We consider first the configuration $B$ for which the dry spacer is sandwiched between two dry PP films of blocking nature, then liquid is in contact with PP interfaces only. The least-squares fit of Equation (1) to the data concerning the B-type configuration is seen to be quite reasonable (dashed line in Figure 2). Over the accessible range of field values, we found that the bulk ionic density ?? $q_{o}$ was field independent. We turn now to the second configuration (case C). It is important to appreciate that the variation of $\tan \delta(E)$ is markedly different from the previous case (Figure 2). We remark that as the field is increased, the losses increase less rapidly than the $B$ case. This is due to the interface effect which strongly modify the charge injection process in the liquid layer as was discussed in [3].

We studied the variation of the light intensity as a function of the ac-voltage excitation. The UV electroluminescence response is not due to partial discharges [10]. As the applied voltage increased, the electroluminescence activity increased. Figure 3 shows that the radiated light intensity is well correlated with the electric losses over two decades. This experimental observation suggests that electroluminescence is related to charge injection and may occur when the carriers collide with luminescence centers contained in the fluid. The spectral response of the emitted light was also performed. Most of the emitted light from electroluminescence occurs in the 400 to $450 \mathrm{~nm}$ band. This is consistent with the fact that any luminescence center which emit a photon in this range of wavelengths must start from an excited level of 2 to $3 \mathrm{eV}$ above the ground state.

\subsection{SPECTRAL ANALYSIS OF LIGHT EMISSION ASSOCIATED WITH THE GROWTH OF STREAMERS}

This part of the study concerns the spectral analysis of light emission associated with the propagation of streamers in a point to plane geometry under impulse voltage conditions. The physical mechanisms governing the formation of these low-density regions are as yet unresolved.

An up-to-date summary of the existing models is given in [11]. The growth rate of streamers in $M / D B T$ is $1.9 \mathrm{~km} \mathrm{~s}^{-1}$ for positive ones and $0.05 \mathrm{~km} \mathrm{~s}^{-1}$ for negative ones $(35 \mathrm{kV}$, electrode gap of $2.2 \mathrm{~mm}$ and radius

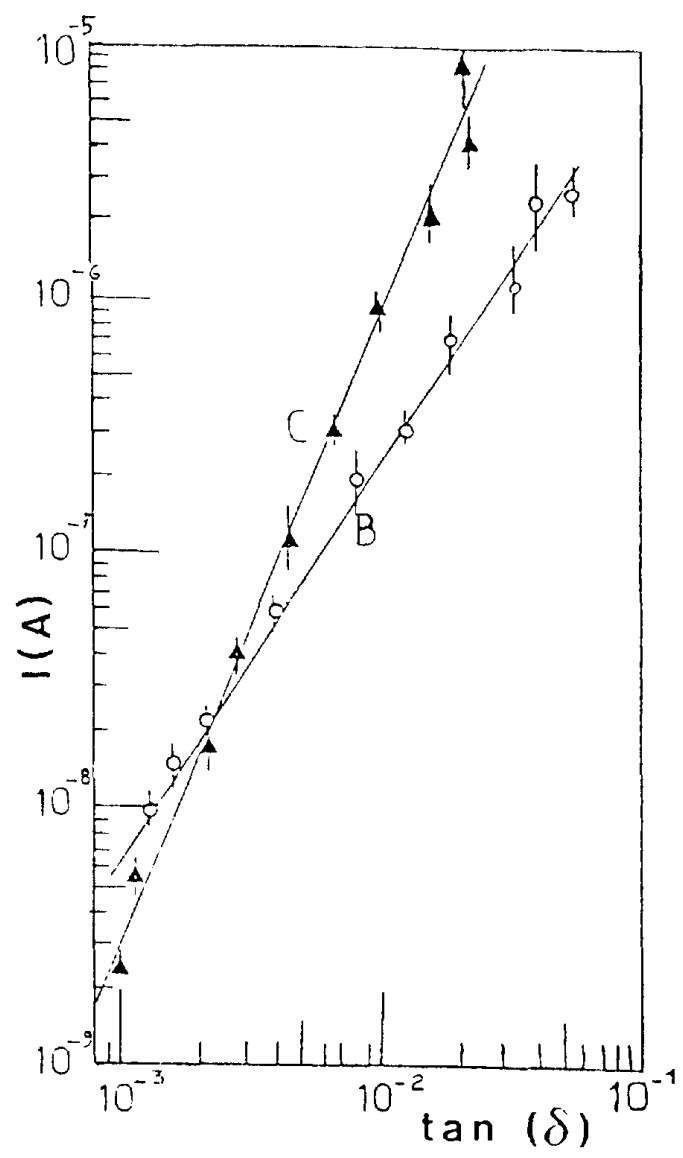

Figure 3.

Correlation between the ac dielectric loss $(50 \mathrm{~Hz})$ and the photomultiplier signal of the radiated light by the luminescent impurities contained in M/DBT. Lines are guides for the eyes. Room temperature.

of curvature of the needle of $3 \mu \mathrm{m}$ ). Similar orders of magnitude of the growth rate were measured in other fluids such as phenylxylylethane (PXE) and cyclohexane $[11,17]$. The use of light emission to characterize the prebreakdown events has been explored by some authors. All have found a close relationship between the current pulse bursts with optical phenomena occurring in streamers development [13-17], suggesting that they are manifestations of the same event, but the interpretation of the emitted light is a subject of current debate in the literature. Sakamoto and Yamada examined in some details the light emission in a series of hydrocarbons during the prebreakdown phase and observed H-Balmer type lines and $\mathrm{C}_{2}-\mathrm{Swan}$ bands [13]. This light emission was thought to be due to dissociation of fluid molecules, to excitation and to ionization in the liquid. Wong and 
Forster studied light emission in $\mathrm{n}$-hexane under lightning impulse voltage ( 1 to $50 \mu \mathrm{s})$ [14]. They observed atomic and molecular $\mathrm{H}$ species, carbon molecules $\left(\mathrm{C}_{2}\right.$ and $\mathrm{C}_{3}$ ) and related this light emission to hot electron processes, similar to that observed in gas discharges. A full description of the processes of formation and growth of streamers, in $\mathrm{M} / \mathrm{DBT}$, under nonuniform field conditions can be found in [17].

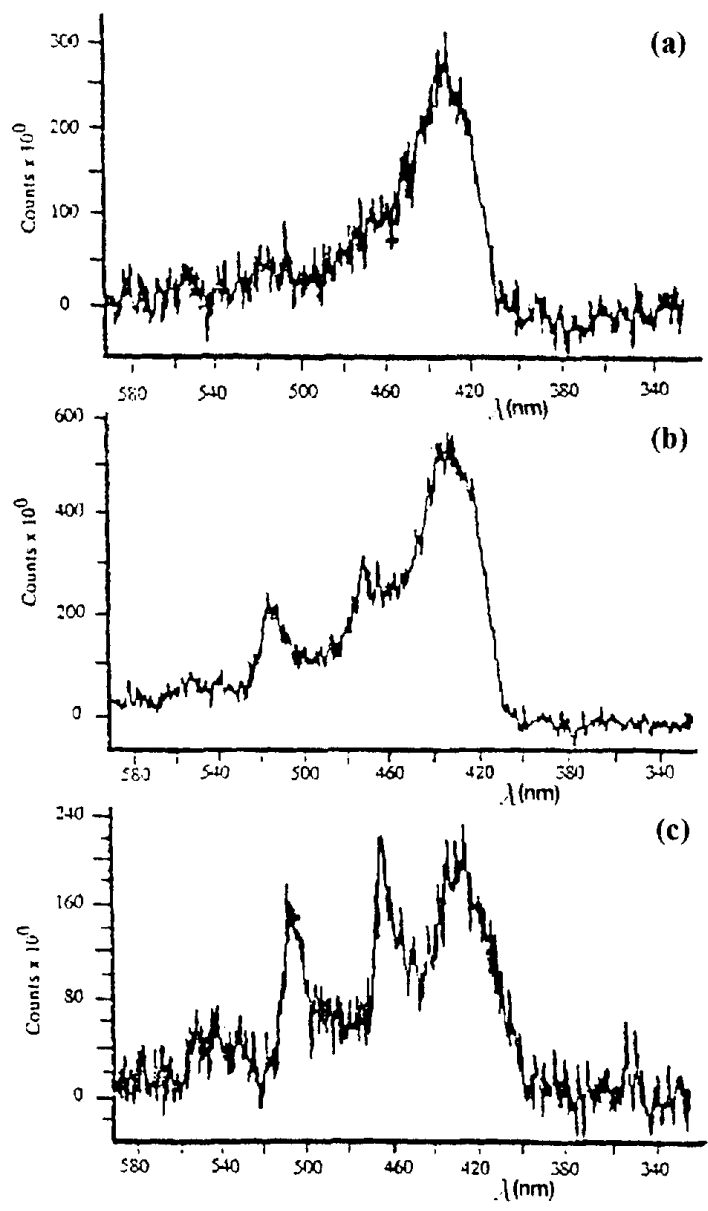

Figure 4

Spectra of radiated light during the development of streamers in M/DBT- step voltage ( 1 to $50 \mu \mathrm{s}$ ). $U=30 \mathrm{kV}$. Spectra corresponds to an accumulation of a tenth of streamers. Room temperature. (a) fluorescence spectrum (no streamer is recorded). (b) negative streamers. (c) positive streamers.

Spectra of the light emitted during the development of positive and negative streamers in $M / D B T$ have been analyzed, under step voltages, at room temperature (Figure 4). Spectra corresponds to an accumulation of a large number of streamers (typically $\sim 10$ to 20 ). These spectra are consistent with the spectral analysis of the specific electroluminescence response. They reveal spectral lines (emerging from a continuum corresponding to molecular fragments) belonging to atomic as well as molecular hydrogen $\left(\mathrm{H}_{2}\right.$ line $)$ and carbonaceous matter $\left(\mathrm{C}_{2}\right.$ Swan bands at 472,506 and $516 \mathrm{~nm}$ ) resulting from the decomposition of the fluid (Figure 4). These characteristic lines are more intense when the point is anode than when it is is cathode: this parallels the fact that positive streamers are much more energetic than the negative ones. Moreover these findings are found to be quite consistent with results obtained by chromatography of the dissolved gases $\left(\mathrm{H}_{2}, \mathrm{CH}_{4}, \mathrm{C}_{2} \mathrm{H}_{4}, \mathrm{C}_{2} \mathrm{H}_{6}\right.$ and $\left.\mathrm{C}_{2} \mathrm{H}_{2}\right)$ produced by dissociation, fragmentation of the fluid molecules and recombination of the molecular fragments $[17,19-22]$. These gases result mainly from vaporization for slow bush-like streamers while for fast filamentary streamers, dissociation and ionization in the liquid are the dominant processes [23]. Finally it is important to note the existence of an important line (428 $\mathrm{nm}$ ) in the spectra (Figure 4(b) and (c) similar to that observed in a virgin liquid (Figure $4(\mathrm{a})$ ). This line originates from a process of excitation in $\mathrm{M} / \mathrm{DBT}$ [21].

\section{CONCLUSION}

$\mathrm{T}$ $\mathrm{HE}$ methodology described here is currently used to evaluate and select new synthetic dielectric fluids for use in the all-film capacitor technology. There do of course remain a number of points to be investigated, regarding the interface influence on the high-field conduction and prebreakdown phenomena in these fluids. In particular, it is of interest to study the mechanisms of electrical conduction into thin liquid layers under high electric stress at high temperatures and containing ionic impurities since it represents the extreme prejudice situation for the insulation. One important question in this regard is to characterize the initial phases of the prebreakdown conduction regimes, i.e. formation of current pulses and bubbles. Another related question is how all of this can be connected to the molecular composition of the fluid. This question has recently been addressed in the study of Forster et al. [8] devoted to the characterization of conduction and breakdown in a series of capacitor impregnants. Efforts now should be made to develop a study of these impregnants which should focus on the prebreakdown regime by using methods of spectral analysis with temporal and spatial resolutions. Work in these directions is currently under progress.

\section{ACKNOWLEDGMENT}

The authors would like to acknowledge the technical assistance of $R$. Riva and $M$. Hilaire during the course 
of this research project. One of us (A. B.) would like to thank also Prof. N. Felici for stimulating discussions and his constant encouragement. Part of the work reported here was performed at LEMD, Grenoble, France.

\section{REFERENCES}

[1] S. Yasufuku, T. Umemura and Y. Yasuda, "Dielectric Properties of Oil-impregnated all Polypropylene Film, Power Capacitor Insulation Systems", IEEE Trans. Electr. Insul., Vol. 13, pp. 403-410, 1978.

[2] S. Yasufuku, T. Umemura, C. Tanii, "Electric Conduction Phenomena and Carrier Mobility Behavior in Dielectric Fluids", IEEE Trans. Electr. Insul., Vol. 14, pp. 28-35, 1979.

[3] C. Brosseau, "Interface Influence on the High-field Conduction Phenomena of a Thin Dielectric Liquid Layer", J. Appl. Phys., Vol. 69, pp. 891-895, 1991.

[4] C. Brosseau, "Electrical Conduction in Impregnants for All-film Power Capacitors", J. Appl. Phys., Vol. 70, pp. 5544-5554, 1991.

[5] T. J. Gallagher, Simple Dielectric Liquids, Oxford University Press, London, 1973.

[6] W. F. Schmitt, "Electronic Processes in Dielectric Liquids", IEEE Trans. Electr. Insul., Vol. 19, pp. 249-276, 1984.

[7] E. O. Forster, "Electric Conduction in Liquid Hydrocarbons", IEEE Trans. Electr. Insul., Vol. 2, pp. 10-15, 1967.

[8] E. O. Forster, C. Mazzetti, M. Pompili and R. Cecere, "The Effect of Molecular Structure on the Properties of Dielectric Fluids", IEEE Trans. Electr. Insul., Vol. 26, pp. 749-754, 1991.

[9] C. Brosseau, "Breakdown of a Thin Dielectric Liquid Layer", IEEE Trans. Electr. Insul., Vol. 27, pp. 1217-1221, 1992.

[10] C. Brosseau, Electrical Conduction and Breakdown Phenomena in Impregnants for All-Film Power Capacitors-Interfacial Aspects, PhD Thesis, Fourier University, Grenoble, 1989, Unpublished.

[11] E. O. Forster, "Progress in the Understanding of Electrical Breakdown in Condensed Matter", J. Phys. D: Appl. Phys., Vol. 23, pp. 1506-1514, 1990.

[12] E. O. Forster, "Progress in the Field of Electric Properties of Dielectric Liquids", IEEE Trans. Electr. Insul., Vol. 25, pp. 45-53, 1990.
[13] S. Sakamoto and H. Yamada, "Optical Study of Conduction and Breakdown in Dielectric Liquids", IEEE Trans. Electr. Insul., Vol. 15, pp. 171-181, 1980.

[14] P. P. Wong and E. O. Forster, "The Dynamics of Electrical Breakdown in Liquids Hydrocarbons", IEEE Trans. Electr. Insul., Vol. 17, pp. 203-220, 1982.

[15] H. Yamashita and H. Amano, "Prebreakdown Density Charge, Current and Light Emission in Transformer Oil under Non-uniform Field", J. Electrostatics, Vol. 12, pp. 253-263, 1982.

[16] K. Arii and I. Kitani, "Optical Studies of Prebreakdown Phenomena in Liquid Hydrocarbons", J. Electrostatics, Vol. 12, pp. 247-252, 1982.

[17] A. Beroual and A. Denat, "Spectral Analysis of the Light Emitted by Streamers in Liquid Dielectrics", C. R. Acad. Sci. Paris, Vol. 306, Série II, pp. 187$192,1988$.

[18] R. E. Hebner, Electro-optical Measurement Techniques, Fast Electrical and Optical Measurements, Vol. 1 Current and Voltage Measurements, Martinus Nijhoff, Boston, 1986.

[19] C. N. R. Rao, Ultra-violet and Visible Spectroscopy, Butterworth, London, 1967.

[20] H. H. Jaffe and M. Orchin, Theory and Applications of Ultraviolet Spectroscopy, Wiley, Newyork, 1962.

[21] A. Beroual, Propagation and Generation of Streamers in Liquids under Step Voltages in Point Plane Geometry, Thèse de Doctorat es Sciences, INPG, Grenoble, France, 1987.

[22] A. Beroual, C. Marteau and R. Tobazeon, "Behavior of Streamers in Liquids under Step Voltages in Point Plane Geometry", IEEE Trans. Electr. Insul., Vol. 23, pp. 955-959, 1988.

[23] N. J. Felici, "Blazing a Fiery Trail with the Hounds", IEEE Trans. Electr. Insul., Vol. 23, pp. $497-503,1988$.

This paper is based on a presentation given at the 11 th International Conference on Conduction and Breakdown in Dielectric Liquids, Baden-Dättwil, Switzerland, July 1993.

Manuscript was received on 25 October 1993, in final form 26 April 1994. 